\title{
CLINICAL AND RADIOGRAPHIC EVALUATION OF THREE CAPPING MATERIALS IN PULPOTOMIZED YOUNG PERMANENT TEETH
}

\author{
Taha $\mathrm{M}^{*}$, Farouk $\mathrm{I}^{* *}$ and El-Bayoumy $\mathrm{S}^{* * *}$
}

\begin{abstract}
This study was to evaluate clinical and radiographic effects of three medicaments (Calcium hydroxide, Biodentine and BAG) on the pulp tissue of young permanent teeth. Methodology: Pulpotomy procedure was performed in thirty young first permanent molars. After that, the radicular pulp is medicated either with biodentine, BAG or $\mathrm{Ca}(\mathrm{OH})_{2}$ and restored with $\mathrm{Zn}$ phosphate cement. After 48 Hours, 4 weeks, 3 months, patients were recalled and data were collected, tabulated, and statistically analyzed. Result: Clinical and radiographic assessments of the three groups revealed 90\%, 60\% and 80\% success rates respectively, after 3 months follow up. Conclusion: Biodentine can be used successfully as a pulpotomy medicament in young permanent teeth.
\end{abstract}

\section{INTRODUCTION}

Dental caries development is considered to involve a triad of indispensable factors, which can be concluded as bacteria in dental plaque, carbohydrates in diet and susceptible teeth ${ }^{(1)}$. Young permanent teeth are recently erupted teeth in which normal physiological apical root closure has not occurred. Normal physiological root closure of permanent teeth may take 2-3 year after tooth eruption, young permanent teeth are in development stage in children from 6 years of age until mid-teens. Human tooth with immature apex is a developing organ ${ }^{(2)}$. It is important to preserve vitality of young permanent teeth through vital pulp therapy. Pulpotomy is surgical removal of the entire coronal pulp, leaving intact the vital radicular pulp within the canals to amputate the infected coronal pulp, neutralize any residual infectious process, preserve the vitality of the radicular pulp, and promote open root apices healing through use of different medicaments ${ }^{(3)}$. Some materials do better than others when placed on exposed pulps due to their ability to prevent bacterial contamination of the pulp ${ }^{(4)}$. Calcium hydroxide became recognized as a valuable pulpotomy material after its use for performing pulpotomy in $1978^{(5)}$. Calcium hydroxide has several disadvantages: It loses its antibacterial capacity when it comes in contact with tissue fluid due to decrease in its alkaline $\mathrm{pH}$, calcium hydroxide is not a good material for sealing against bacterial penetration as bacteria can readily penetrate any remaining calcium hydroxide after its initial antibacterial action is over, it completely depends on the overlying restorative material to prevent bacterial penetration to the pulp ${ }^{(6)}$.

Biodentine (calcium silicate-based material) is other medicament that has several advantages which include good sealing ability, adequate compressive strength, and short setting time, which provide a significant clinical advantage over other comparable materials ${ }^{(7,8)}$. It is biocompatible and also shows bioactivity $^{(9,10)}$. Bioactive glass (BG) is other medicament which has been widely used in bone regeneration, however, reports on the biological effects of BG on dental pulp cells are rare. ${ }^{(11)}$

\footnotetext{
* Demonstrator, Pediatric Dentistry and Oral Health Department, Faculty of Dental Medicine (Assuit), Al-Azhar University ** Lecturer of Pediatric Dentistry and Oral Health Department, Faculty of Dental Medicine, Boy's, Cairo, Al-Azhar University *** Professor and Head of Pediatric Dentistry and Oral Health Department, Faculty of Dental Medicine, Boy's, Cairo, Al-Azhar University
} 
The objective of this study was to compare between the clinical and radiographic effects of three medicaments (Calcium hydroxide, bidentine and BAG) on the pulp tissue of young permanent teeth.

\section{MATERIALS AND METHODS}

The present study was a longitudinal study comprising thirty first permanent molars, obtained from child patients with ages ranged from (6-9) years. Patient had, at least one deeply carious vital first permanent molar with incompletely formed roots. A complete history was obtained and a thorough clinical examination was completed for each selected child. The selected molars were divided randomly into three equal groups:

Group A): Comprising 10 young permanent molars that were treated with biodentine (Septodont).

Group B): Comprising 10 young permanent molars that were treated with BAG material (Biogran-biomet3i).

Group C): Comprising 10 young permanent molars that were treated with Dycal ${ }^{\circledR}$ Radiopaque Calcium Hydroxide Composition (Dentsply).

\section{Pulpotomy procedure}

A surgically clean technique used throughout the procedure. The entire roof of the pulp chamber was removed. The pulp stumps cleanly excised with no tags of tissue extending across the floor of the pulp chamber. Cotton pellets moistened with normal saline were placed in the pulp chamber and allowed to remain over the pulp stumps until a homeostasis performed. Following the access cavity procedures and control of hemorrhage, the different capping materials were applied according to manufacture instructions. Protective layer of $\mathrm{Zn}$ phosphate cement was placed over the capping material in each of groups to provide an adequate seal.

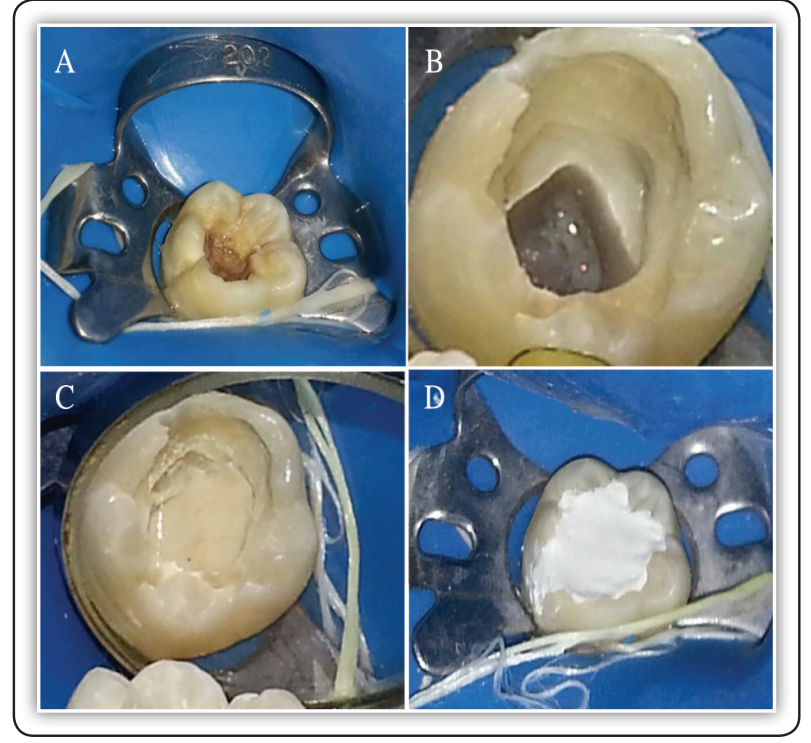

FIG (1) Biodentine pulpotomy. (A) Case No 8 before ttt. (B) Gaining access and cavity preparation. (C) Placement of biodentine. (D) Temporary restoration with z.ph cement.

\section{RESULTS}

\section{Clinical and radiographic findings of group A:}

Clinical and radio-graphical findings of the young permanent molars treated with Biodentine at different intervals are listed in table (5). All cases had no pain at the post- operative evaluation. At the following review appointments (4 weeks, 3 months), in one case was associated with swelling and recorded as treatment failure cases. For this reason, Apexification and/or endodontic treatment were performed for it. Radiographically, only 1 molar showed evidence of widening in the periodontal membrane space. In addition, one of them exhibited periapical and furcation radiolucencies and considered as treatment failure cases. Fig. (2) At last recall visit (3months) one molar have periapical and furcation involvement and increasing radiolucency and this accompanied with widening in the periodontal membrane space and considered as treatment failure case.

\section{Clinical and radiographic findings of group B:}

It was found that 6 teeth $(60 \%)$ of the group were responded positively to BAG material and appear 


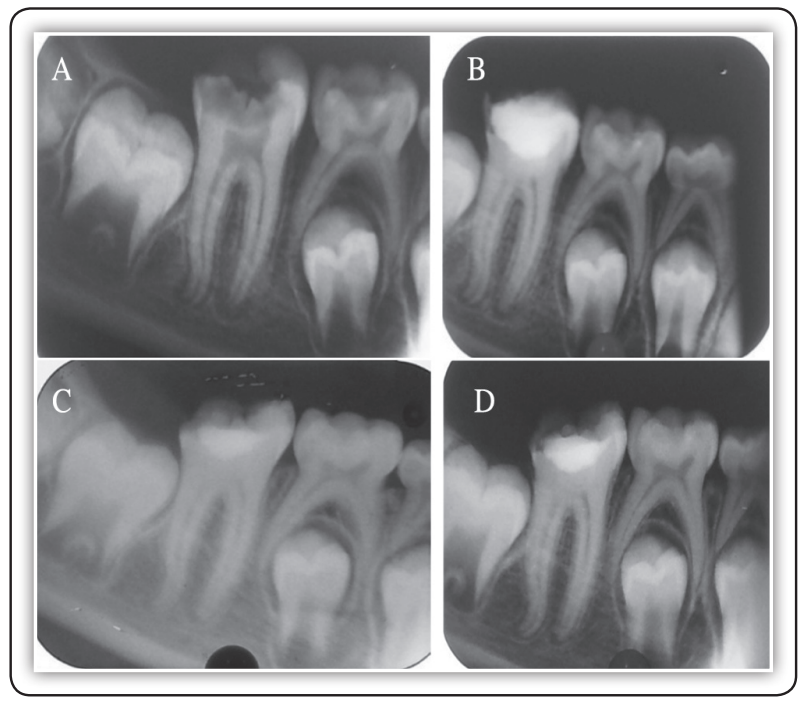

Fig. (2) Radiographic feature of case 10 treated with biodentine pulpotomy (Group A). A- (Preoperative), B- (48hr posttreatment), C- (4 weeks), D-(3 months)

normal as evaluated and measured by clinical and radiographic assessments for 3 successive months while the remaining 4 teeth ( $40 \%$ ) failed to respond positively. For this reason, Apexification and/or endodontic treatment were performed for them.

\section{Clinical and radiographic findings of group $\mathrm{C}$ :}

Clinical findings of the young permanent molars treated with Calcium hydroxide at different intervals. Two cases had pain at the post-operative evaluation. At the following review appointments (48hr). In two of them pain was associated with swelling and increased mobility (grade II) and recorded as treatment failure cases. For this reason, Apexification and/or endodontic treatment were performed for them. Radiographically Only 2 molars showed evidence of widening in the periodontal membrane space. In addition, these molars exhibited periapical and furcation radiolucencies and considered as treatment failure cases. At last recall visit (3months) tow molars have periapical and furcation involvement and increasing radiolucency and this accompanied with widening in the periodontal membrane space and considered as treatment failure cases.

\section{Comparison between the three groups $\mathrm{A}, \mathrm{B} \& \mathrm{C}$ :}

On comparing the success rate of the groups, A, B \& C. using the F-test.

\begin{tabular}{|c|c|c|c|}
\hline Character & Biodentine (A) & BAG (B) & $\begin{array}{c}\text { Calcium } \\
\text { hydroxide (C) }\end{array}$ \\
\hline Sub. No. & 10 & 10 & 10 \\
\hline Success cases & 9 & 6 & 8 \\
\hline Percentage & $90 \%$ & $60 \%$ & $80 \%$ \\
\hline Failed cases & 1 & 4 & 2 \\
\hline Percentage & $10 \%$ & $40 \%$ & $20 \%$ \\
\hline S.D. & 0.330719 & 0.489898 & 0.4 \\
\hline Sig. & A:C $=.035$ & & B:C $=.060$ \\
\hline
\end{tabular}

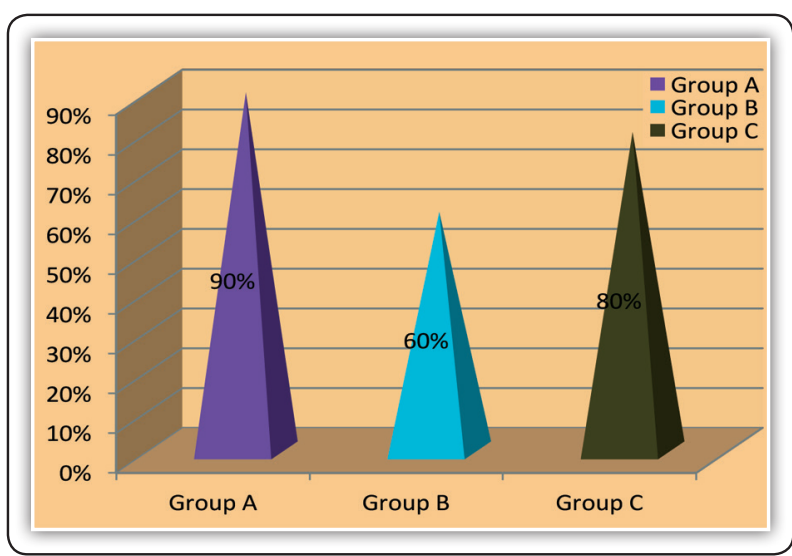

FIG (3) Success rate of the groups (A), (B) and (C).

\section{DISCUSSION}

When biodentine was used in this study as a pulpotomy dressing (group A), a success rate was (90\%) which may be due to better sealing ability with a reduced setting time, anti-bacterial action and dentine bridge formation, where biodentine increased calcium and TGF- 31 secretion from pulp cells when placed in direct contact with it, leading to induction of angiogenesis, cell differentiation and mineralization. This is in agreement with other searches ${ }^{(12,13) .}$ In study of Nowicka et al. ${ }^{(12)}$, 
the success rate of biodentine pulpotomy was $95 \%$, which may be due to high alkalinity and better marginal sealing that prevent marginal leakage. Kusum et al. ${ }^{(13)}$, found that success rate of biodentine pulpotomy was $100 \%$ at 6 months period follow-up and this may be due to bioactivity, short setting time (12 minutes), good handling, low solubility and mechanical properties similar to dentine.

In the present study, it was found that the success rate of BAG (group B) was 60\%, which may be attributed to antibacterial action and biocompatibility of BAG where high failure rate may be due to low sealing ability and marginal adaptation of BAG, which allows bacterial leakage. This percentage was nearly in agreement with the results of other studies ${ }^{(14,15)}$. In study of Jabbarifar et al. ${ }^{(14)}$, success rate was $70 \%$ of BAG after 3 months which may be due to dentine inductivity of BAG to form barrier against microbes. Where failure rate was $30 \%$ in form a moderate inflammation, which may be due to protection response from pulp to any foreign materials, he have shown that healing pulpal reactions are more dependent on the capacity of capping materials to prevent bacterial microleakage rather than the specific properties of the materials themselves. Hoghood et al. ${ }^{(15)}$, they had reported $70 \%$ success rate which may be due to biocompatibility, osteoconductivity and antibacterial effect of BAG.

In the present study the success rate in $\mathrm{Ca}(\mathrm{OH}) 2$ (group C) was (80\%) and this result may be due to its antimicrobial properties which are derived from the high $\mathrm{PH}$, which produced an environment that was not conductive for bacterial growth. These results are in agreements with other studies ${ }^{(16,17)}$. In study of Yildiz et al. ${ }^{(16)}$, they concluded that clinical and radiographic success rate was $(85 \%)$ in the $\mathrm{Ca}$ $(\mathrm{OH}) 2$ group after 30 months and this may be due to bioactivity and biocompatibility of $\mathrm{Ca}(\mathrm{OH}) 2$. El Meligy et al. ${ }^{(17)}$, had reported that clinical and radiographic success rates of $\mathrm{Ca}(\mathrm{OH}) 2$ was $87 \%$ at 6 and 12 months postoperative evaluations and this may be due to high alkalinity $\mathrm{PH}$ that made it bacterioststic agent and failure rate was $13 \%$ at 12-month evaluation, and this failure usually due to bacterial contamination through microleakage where $\mathrm{Ca}(\mathrm{OH}) 2$ have low sealing ability and through the poor dentine bridge at the pulpotomy site. This contains tunnels that may result in infection and necrosis of the pulp. ${ }^{(18)}$

\section{CONCLUSIONS}

1. Biodentine proved better clinical and radiographic result as a pulp medicament than bioactive glass and calcium hydroxide, but this with insignificant difference.

2. BAG recorded good clinical and radiographic results as pulp capping medicament in treatment of vital young permanent teeth.

3. All three tested materials enhancing root formation "elongation" without significant difference, without any change in periodontal tissue.

\section{REFERENCES}

1. Nat S. Comparison of relationship between salivary electrolyte levels and dental caries in children with Down syndrome. BioMed.2015; 6: 144-148.

2. Jeena S. Young permanent teeth and its clinical application in pedodontia. Christian Dental College Ludhiana 2009.

3. Bergenholtz $G$ and Spångberg L. Controversies in endodontics.Crit Rev Oral Bio Med. 2004; 15:99-114.

4. Cox F, Keall L, Keall J, Ostro E, Bergenholtz G. Biocompatibility of surface-sealed dental materials against exposed pulps. J Prosthet Dent. 1987; 57:1-8.

5. Cvek M. A clinical report on partial pulpotomy and capping with calcium hydroxide in permanent incisors with complicated crown fractures. J Endod.1978;4:232-7.

6. Bakland L. Revisiting traumatic pulpal exposure: Materials, management principles, and techniques. Dent Clin North Am. 2009; 53:661-73.

7. Han L and Okiji T. Uptake of calcium and silicon released from calcium silicate-based endodontic materials into root canal dentine. Int Endod J. 2011; 44:1081-7.

8. Koubi G, Colon P, Franquin J, Hartmann A, Richard G, Faure M, et al. Clinical evaluation of the performance and 
safety of a new dentine substitute Biodentine, in the restoration of posterior teeth: a prospective study. CLIN Oral Investig. 2013; 17:243-9.

9. Laurent P, Camps J, De Méo M, Déjou J, About I. Induction of specific cell responses to a $\mathrm{Ca}$ (3) $\mathrm{SiO}$ (5): based posterior restorative material. Dent Mater.2008;24:1486-94.

10. Laurent P, Camps J, About I. induces TGF-b1 release from human pulp cells and early dental pulp mineralization. Int Ended J. 2012; 45:439-48.

11. Wang S, Gao X, Gong W, Zhang Z, Chen X, Dong Y. Odontogenic differentiation and dentin formation of dental pulp cells under nanobioactive glass induction. Acta Biomater. 2014 ;10:2792-803.

12. Kaur H. Biodentine Pulpotomy in Mature Permanent Molar. Journal of Clinical and Diagnostic Research.2016.

13. Kusum B, Rakesh K, Richa K. Clinical and radiographical evaluation of mineral trioxide aggregate, biodentine and propolis as pulpotomy medicaments in primary teeth. Restor Dent Endod. 2015; 40(4): 276-285.
14. Jabbarifar E, Mohammad S, Ahmadi N . Histopathologic Responses of Dog's Dental Pulp to Mineral Trioxide Aggregate, Bio Active Glass, Formocresol, Hydroxyapatite, Dent Res J 2007; 4(2): 83-87.

15. Haghgoo R, Ahmadvand M. Evaluation of pulpal response of deciduous teeth after direct pulp capping with bioactive glass and mineral trioxide aggregate. Department of Pediatric Dentistry, Dental School, Shahed University, Tehran, Iran, 2016; 7: 332-335.

16. Yildiz E, Tosun G. Evaluation of formocresol, calcium hydroxide, ferric sulfate, and MTA primary molar pulpotomies. Eur J Dent. 2014; 8(2): 234-240.

17. El Meligy O, Avery D. Comparison of Mineral Trioxide Aggregate and Calcium Hydroxide as Pulpotomy Agents in Young Permanent Teeth (Apexogenesis). Pediatric Dentistry .2006; 28:5.

18. Mohammadi Z, Dummer P. Properties and applications of calcium hydroxide in endodontics and dental traumatology. International Endodontic Journal.2011;44: 697-730. 
